\title{
ASSISTÊNCIA JUDICIÁRIA PARA OS REEDUCANDOS (AS) DO PRESÍDIO SANTA AUGUSTA DE CRICIÚMA/SC
}

\author{
AUGUSTA CRICIÚMA / SC \\ Larissa Alves Benitez ${ }^{1}$ \\ Tamires do Nascimento Teixeira ${ }^{2}$ \\ Alfredo Engelmann Filho ${ }^{1}$ \\ Karin Martins Gomes ${ }^{1}$ \\ Leandro Alfredo da Rosa ${ }^{1}$
}

JUDICIAL ASSISTANCE FOR REEDUCATION (AS) THE PRISON OF SANTA

\begin{abstract}
RESUMO
A extensão possibilita vincular a teoria com a prática na comunidade. Com a necessidade de assistência, tanto jurídica quanto psicológica, dentro dos estabelecimentos prisionais, entra a atividade e atuação do projeto de Assistência Judiciária aos Reeducandos do Presídio Santa Augusta, que possibilita aos detentos, que não têm condições de constituir defensor particular e que não são atendidos pela Defensoria Pública, a possibilidade de acesso aos processos de Execução Penal através da análise dos benefícios da Execução Penal, previstos na Lei de Execuções Penais. Noutro viés, este projeto também oferece assistência psicológica, através da aplicação do exame criminológico, avaliação esta que visa afirmar se o apenado aceita a pena que lhe foi imposta, bem como assimila a condição atual de encarcerado, verificando-se se possui expectativas positivas com relação ao seu reingresso na sociedade. Em outras palavras, o projeto visa, por suas atividades, oferecer a possibilidade de ressocialização, ideia bem aceita pela comunidade, com atuação que vem sendo alvo de excelentes críticas.

Palavras-chave: Direito; Psicologia; Assistência Judiciária; Ressocialização.
\end{abstract}

ABSTRACT
The extension enables link theory with practice in the community. With the need for assistance, both legal and psychological within the prisons, enters the activity and performance of the Legal Aid project to reeducation of Presidio Santa Augusta, which allows detainees who can not afford to be particular defender and that are not served by Public Defender, the possibility of access to files of Penal Execution by analyzing the benefits of Criminal Enforcement, provided for in the Criminal Law. In another bias, this project also offers psychological assistance, through the application of criminological examination, evaluation aimed at this state if the convict accepts the penalty imposed on him, and assimilates the current condition of imprisoned, verifying that you have positive expectations relation to its re-entry into society. In other words, the project aims for its activities, offer the

\footnotetext{
${ }^{1}$ Universidade do Extremo Sul Catarinense.

${ }^{2}$ Universidade do Extremo Sul Catarinense. Autora para correspondência: Rua Dona Beta, $\mathrm{n}^{\circ}$ 198. Bairro Jaqueline. Içara- SC. CEP 88820-000. Email: tamynascimentoteixeira@ hotmail.com.
} 
possibility of rehabilitation, idea well accepted by the community, with performance that has been the subject of rave reviews.

Keywords: Law; Psychology; legal aid; resocialization.

\section{INTRODUÇÃo}

O Presídio Santa Augusta e a Penitenciária Sul, estabelecimentos prisionais situados na cidade de Criciúma/SC, não diferem da realidade nacional no que diz respeito ao sistema carcerário caótico e defasado que, infelizmente, não cumpre sua função principal no papel de ressocialização e humanização da pena e do cárcere. A triste situação deve-se, dentre outros fatores, também, à superlotação que impede a execução de projetos a serem desenvolvidos. É necessária uma ação conjunta, contínua e urgente focando, principalmente, aqueles que já cumprem penas e esperam pelo deferimento dos benefícios da Execução Penal, previstos na Lei de Execuções Penais, como a progressão de regime, livramento condicional, saída temporária, comutação de penas, indulto, remição, trabalho externo ao presídio ou liberação de pecúlio para assistência à família do recluso ou egresso do sistema prisional, propiciando o contato do reeducando (a) com sua família, bem como com o trabalho que edifica e ocupa mentes vazias.

O projeto “Assistência Judiciária para os Reeducandos (as) do Presídio Santa Augusta de Criciúma/SC", vinculado ao curso de Direito da UNESC, com apoio do curso de Psicologia, proporciona aos apenados alento, esperança e perspectiva, tendo em vista que serão revistas suas penas, o tempo restante de prisão e os benefícios a que eles têm direito, bem como orientá-los no tocante aos seus deveres para que possam conduzir o cumprimento da pena imposta de forma disciplinada e reta, com comportamento adequado, um dos requisitos fundamentais, juntamente com o critério objetivo (tempo de pena) para obtenção dos benefícios da execução penal. A par disso, referidos reeducandos (as), após análise da situação prisional na qual se encontram, terão seus pedidos imediatamente encaminhados para o Juízo da Execução Penal da comarca de Criciúma/SC, caso necessitem de decisão judicial como, por exemplo, remissão de pena, indulto, comutação, saída temporária, progressão de regime, defesa nos incidentes de regressão de regime por prática de falta grave, liberação de pecúlio para assistência à família, dentre outros. Os Defensores Públicos nomeados no concurso que iniciou as atividades da Defensoria Pública no estado de Santa Catarina, indicados para a comarca de Criciúma, não atenderão a demanda da população carcerária, fazendo com que ocorram atrasos prejudiciais na análise dos pedidos das pessoas que cumprem pena nos ergástulos catarinenses. 
Além disso, preceitua Prado (2013, p. 474) que

o preso, durante o cumprimento da pena, conserva todos os direitos não atingidos pela perda da liberdade, impondo-se a todas as autoridades o respeito à sua integridade física e moral (art. 38, CP). Também a Lei de Execução Penal preceitua com clareza que "ao condenado e ao internado serão assegurados todos os direitos não atingidos pela sentença ou pela Lei" (art. $3^{\circ}$ ). Com efeito, o próprio texto constitucional em vigor determina ser assegurado aos presos "o respeito à integridade física e moral" (art. $5^{\circ}, \mathrm{XLIX}$ ), já que é expressamente previsto que "ninguém será submetido a tortura, nem a tratamento desumano ou degradante" (art. $5^{\circ}$, III, CF).

A participação efetiva da universidade, professores e acadêmicos, faz-se necessária em trabalho permanente, visto que a população carcerária renova-se quase que diariamente. A longo prazo, ter-se-á amenizado uma situação flagrante de risco de rebeliões e fugas, o que beneficia, diretamente, a sociedade criciumense.

O projeto visa promover o atendimento de todos os apenados carentes e desprovidos de condições de contratar advogado, resgatando o sentimento de atenção voltada aos reeducandos e proporcionando uma nova perspectiva e esperança com expectativa de término do cumprimento da pena e possibilidade de retorno ao seio familiar e da sociedade com uma nova visão de mundo e de criminalidade, resgatando sentimentos de autoestima e afeição ao trabalho honesto e digno.

A triagem inicial, com o atendimento completo de todos os apenados e apenadas, visa identificar aqueles que mais carecem de acesso à justiça, dentre os que já possuem amparo jurídico com a contratação de advogados particulares, evitando que o projeto descompasse a ética profissional da advocacia, primando pela união de esforços no mesmo sentido.

A informação clara, atual e constante ao reeducando (a) proporciona dignidade e respeito à Lei de Execução Penal, tranquilizando, inclusive, seus familiares que, muitas vezes, também se encontram desprovidos de informações e recursos, o que gera muita angústia e, por vezes, revolta.

A relevância acadêmica e social das atividades previstas visa atender segundo a Lei $\mathrm{n}^{\circ}$ 8.74293 da Lei Orgânica da Assistência Social - LOAS e Resolução do Conselho Nacional de Assistência Social - CNAS no 27 de 19/09/2011 previstas nos editais de extensão e que privilegiam os aspectos filantrópicos da UNESC enquanto Universidade Comunitária, já que a demanda da clientela se encontra em situação de vulnerabilidade social, a qual terá um suporte técnico-científico jurídico e psicológico como instrumento promotor de cidadania. Outro ponto relevante é o de oferecer um laboratório prático para acadêmicos dos cursos de Direito e Psicologia. 
Dentre os objetivos do Projeto:

Objetivo Geral:

- Prestar atendimento judiciário e psicossocial aos reeducandos (as) do Presídio Santa Augusta de Criciúma/SC que não possuem advogado, elaborando pedidos para a concessão de benefícios da Execução Penal, tais como remição, indulto, livramento condicional, progressão de regime, liberação de pecúlio, dentre outros, bem como auxiliar na organização de pastas e arquivos dos reeducandos e encaminhar ao Juízo da Vara de Execuções Penais, em atendimento à linha de extensão no 47, prevista no item 5.1.1, do edital no 21/2013 UNACSA.

Objetivos Específicos:

- Possibilitar que os reeducandos (as) do Presídio Santa Augusta de Criciúma/SC, que não têm condições de constituir defensor, tenham acesso à justiça, benefícios e serviço de qualidade com igualdade de direitos no acesso ao atendimento às necessidades sociais da população carcerária, obtendo assistência judiciária para o encaminhamento dos pedidos para a concessão de benefícios de execução penal;

- Organizar as pastas individuais de cada reeducando (a) no referido estabelecimento, de forma a disponibilizar as informações sobre o cumprimento de pena e dos prazos de benefícios de execução penal;

- Promover reuniões com os representantes de órgãos ligados à implementação das políticas criminais e de execução de pena, como Poder Judiciário, Ministério Público, OAB, DEAP, Secretaria de Justiça e Cidadania, Secretaria de Segurança Pública, Polícia Civil e Militar para verificar as maiores carências da população prisional, bem como os avanços positivos e negativos do projeto, tanto na fase inicial, quanto na fase de execução, visando atingir os objetivos traçados;

- Orientar os (as) acadêmicos (as) do curso de Direito para a elaboração de peças jurídicas específicas do processo de execução penal, propiciando a aplicação prática dos conhecimentos obtidos em sala de aula;

- Sensibilizar os (as) acadêmicos (as) do curso de Direito e de Psicologia para a problemática carcerária local, contribuindo para a formação cidadã dos (as) estudantes, futuros profissionais da área jurídica e da psicologia social.

Historicamente, a universidade foi construída interligada a uma missão com a sociedade, de informar e transmitir o saber produzido. Este saber nunca se pretendeu neutro, mas esteve envolvido aos interesses sociais que lhe deram origem. Nesse sentido, assinala Fagundes (1986, p. 24): 
A universidade, enquanto instituição social - quer em outros países, quer no Brasil é perpassada pela lógica do contexto sócio-econômico, político e cultural que a circunscreve. O que se deseja salientar é que a problemática universitária não se esgota em si mesma, e, por conseguinte, não pode ser tratada isoladamente ou de forma dicotômica - como se a sociedade e a universidade se constituíssem em entidades autônomas - mas de maneira dialética, em suas relações recíprocas.

Observa-se que a universidade, enquanto espaço de produção e difusão do conhecimento, deve estar intimamente ligada às questões sociais que a cerca, sob risco de perder a consciência da realidade e de tornar incipientes os resultados conquistados nos âmbitos do ensino e da pesquisa. É a retroalimentação da problemática social que estimula na universidade a produção do conhecimento, já que procura instrumentalizar os conceitos teóricos para a proposição de alternativas viáveis, tornando viva a relação teoria e práxis. Também os conteúdos acumulados na pesquisa e no ensino precisam ser comunicados para aqueles que não estão na universidade, mas estão dispostos a participar do que foi produzido e têm uma contribuição a dar para o desdobramento deste conhecimento. A extensão deve ser vista não meramente como uma prestação de serviços assistencialista, nos espaços abandonados pelo Estado, mas como uma atividade inerente à própria concepção de universidade, ao lado da pesquisa e do ensino. Uma extensão transformadora da realidade deve ser entendida como uma forma de comunicação com os cidadãos extramuros da universidade, cientes de que estes possuem muito a ensinar para o corpo docente, pois carregam experiências diferenciadas da realidade vivenciada por estes.

Ademais, vale ressaltar que a própria Lei de Execuções Penais (Lei $n^{\circ}$ 7.210/84) estabelece, em seu art. $4^{\circ}$, a necessidade de cooperação da própria comunidade nas atividades ligadas à execução penal.

Neste sentido, ensina Mirabete (2002, p. 43):

Preconiza o art. $4^{\circ}$ da Lei de Execução Penal que o Estado deverá recorrer à cooperação da comunidade nas atividades de execução da pena e da medida de segurança, pois, segundo o que consta da exposição de motivos, nenhum programa destinado a enfrentar os problemas referentes ao delito, ao delinqüente e à pena se completaria sem o indispensável e contínuo apoio comunitário. Outro ponto inovador da lei é o de que o Estado deve recorrer à cooperação da comunidade como condição essencial para que seja alcançado o objetivo de facilitar a futura reinserção do condenado à vida social.

O presente projeto específico na área de Direito, que faz parte de uma ação global da UNESC junto ao Presídio Santa Augusta e Penitenciária Sul, além de inédito na região Sul de Santa Catarina, trará inúmeros benefícios para os reeducandos (as), familiares, acadêmicos do Direito e da Psicologia, orientados por professores dos respectivos cursos, tendo muito a contribuir na construção pessoal e coletiva de conhecimento teórico e prático.

O Conselho Federal de Psicologia (2010, p. 9) afirma que 
[...] o agravamento da crise vivida no sistema penitenciário e o fato de o Brasil ser país que possui uma das maiores populações carcerárias do mundo exigem mais do que nossa contribuição na construção de atribuições, competências e possibilidades de uma prática profissional voltada para a integração social. Exigem-nos ampliação do diálogo com movimentos sociais e construção de parcerias [...] compreendendo que o modelo de privação de liberdade não faz avançar a cidadania, piora os vínculos sociais e produz exclusão.

Vale lembrar, mutatis mutandis, que as atividades exercidas pelas ações vinculadas a este projeto de extensão, atendem aos critérios da Lei $n^{\circ} 8742 / 93$, uma vez que promove atendimento às necessidades sociais sobre as exigências de rentabilidade econômica, beneficiando a família do recluso (liberação de pecúlio), no atendimento aos reclusos que não possuem condições de contratar advogado para defesa dos seus direitos e acesso à Justiça. Respeita a dignidade do cidadão encarcerado, a sua autonomia e ao seu direito a benefícios e serviços de qualidade, prestado por professores habilitados na área do Direito Penal, propiciando igualdade de direitos no acesso ao atendimento.

\section{METODOLOGIA}

O público/comunidade-alvo são os Reeducandos (as) do Presídio Santa Augusta de Criciúma/SC.

Quanto à execução de trabalho do projeto será utilizada da seguinte forma:

Momento de aproximação com as instituições: coordenadores do projeto promoverão reunião com os órgãos envolvidos com a Segurança Pública em Criciúma e no Estado, demonstrando os objetivos do projeto, sem ferir as funções estatais já pré-definidas e servindo como ferramenta de auxílio em igualdade de direitos e acesso a atendimento de qualidade prestado por professores habilitados na área da Execução Penal.

Momento de Intervenção no Presídio Santa Augusta: Os atendimentos são realizados dentro da carga horária estabelecida nos editais e demonstrou ser muito positivo. Tendo em vista a precária estrutura física que possui o Presídio Santa Augusta, inúmeros elogios prestados por parte dos agentes prisionais e funcionários do Presídio, pela educação, empenho e dedicação dos alunos bolsistas e voluntários, coordenadores e demais envolvidos com o projeto de extensão da UNESC, bem como por parte dos próprios apenados (as) e de seus familiares.

Oportuno mencionar que o projeto iniciou com atendimento às mulheres grávidas ou com filhos nos berçários da unidade prisional, o que gerou acolhida imediata por parte destas e seus familiares e, posteriormente, com os homens. Todos os atendidos não possuíam condições de constituir defensor cujos processos foram revistos e prestadas as devidas informações a respeito da execução penal. 
Os reflexos das ações desenvolvidas pelo projeto proporcionam espaço de reconhecimento da UNESC em termos de mídia: os coordenadores do Projeto bem como alunos bolsistas participaram de programas de rádio e televisão, a citar, Programa Adelor Lessa (Rádio Som Maior), Rádio Eldorado, TV Litoral Sul-Canal 20 da NET, portais de notícias da internet como portal SATC, portal da UNESC, participação em reuniões e encontros, como o Congresso Regional Sul de Pastorais Carcerárias do Estado de Santa Catarina, com a presença de representantes de todo o Estado, onde foi possível demonstrar aos presentes o Projeto desenvolvido pela UNESC e, segundo informações dos representantes de pastorais carcerárias de todo o estado, um projeto inédito e que seria levado ao conhecimento das demais Universidades do Estado. Por isso, a importância de dar-se prosseguimento com as atividades aqui propostas mantendo-se a possibilidade de acesso à justiça à população carcerária dos estabelecimentos penais de Criciúma.

Momento de Encaminhamento: Os pedidos judiciais serão encaminhados ao Fórum para análise do Juiz responsável pela Execução Penal, Dr. Rubens Sérgio Salfer.

Momento de Prestação de Contas: Na medida em que o Juiz for decidindo acerca dos pedidos propostos pela equipe do projeto, retomar as entrevistas com os reeducandos (as), informando-os do resultado dos pedidos formulados, demonstrando efetividade no trabalho realizado.

Momento de Avaliação: Periodicamente serão promovidas reuniões com representantes do Poder Judiciário, Ministério Público, OAB, DEAP, Secretaria de Justiça e Cidadania, Secretaria de Segurança Pública, Polícia Civil e Militar para manter todos informados do andamento dos trabalhos e fazer reavaliações contínuas.

Momento de acompanhamento: Finalizada a primeira etapa do projeto, os acadêmicos continuarão a segunda etapa do mesmo, acompanhando o andamento dos processos no Fórum.

Momento de elaboração dos relatórios, para posterior apresentação à UNACSA.

Momento de socialização das experiências: Em salas de aula, nos cursos de Direito e Psicologia, e em eventos da UNESC, salientando que o projeto ora apresentado foi premiado na última Semana de Ciência e Tecnologia da UNACSA, na modalidade apresentação oral.

\section{RESULTADOS}

O projeto teve início das atividades em abril de 2012, com assistência judiciária e acompanhamento semanal da execução penal. Aqueles que preenchiam os requisitos exigidos por lei tiveram os benefícios concedidos. Caso contrário, passaram a ter ciência de como 
deveriam agir e quanto esperar para alcançar a satisfação dos requisitos para benefícios futuros.

Além das análises e confecções dos pedidos, o Projeto auxiliou o Presídio Santa Augusta na análise dos cálculos da execução penal e todos os outros benefícios elencados na Lei $n^{\circ} 7210 / 84$, com remessa dos pedidos à Vara de Execuções Penais.

Dois anos após o início das atividades do projeto, com quase 900 atendimentos feitos, foi integrada a atuação da psicologia, cuidando da parte da assistência psicológica e social, através da aplicação do exame criminológico nos casos necessários.

A comunidade, assim como o Poder Judiciário, e também o próprio estabelecimento prisional onde ocorrem as atividades, tem apreciado a atuação e incentivado a continuação do projeto, mostrando assim que os resultados são claramente positivos e satisfatórios.

\section{DISCUSSÃo}

Com o projeto, as extensionistas puderam colocar a teoria estudada em sala de aula em prática, através das assistências judiciária e psicológica prestadas. Viver a extensão proporciona uma experiência em conjunto com a comunidade, possibilitando uma troca de saberes, o que contribui para um melhor aprendizado acadêmico e, consequentemente, uma mais completa formação.

Noutra perspectiva, o projeto colabora para um melhor andamento das atividades realizadas dentro do estabelecimento prisional. Com a grande demanda de detentos e, consequentemente, de processos, os profissionais que lá atuam ficam sobrecarregados, sendo, portanto, de grande ajuda a atuação da extensão para auxiliá-los a diminuir a carga de trabalho.

Quanto aos detentos, a extensão cuida para que seus direitos sejam atendidos e não fiquem a mercê do desamparo e do abandono, pois a grande problemática do encarceramento é a insuficiência de assistência judiciária para aqueles que não possuem recurso financeiro para constituir advogado. E é nesse ponto que a extensão atua, proporcionando as diligências cabíveis aos apenados que dependem somente do atendimento ofertado pelo setor jurídico do presídio.

Sob outro ângulo, a comunidade é indiretamente beneficiada pelo projeto por, além de proporcionar uma possibilidade de ressocialização ao preso que, após cumprir integralmente a sua pena, retornará a sociedade com uma nova perspectiva de vida, proporciona também uma segurança à população, devido à redução de rebeliões provocadas pela falta de assistência judiciária. 
Assim sendo, é possível afirmar que o projeto vem atendendo as expectativas em diversos âmbitos, fornecendo resultados satisfatórios, ampliando seu alcance e gerando visibilidade para os cursos de Direito e Psicologia e, principalmente, para a UNESC, que possibilita aos acadêmicos envolvidos a vivência do ensino, pesquisa e extensão.

\section{REFERÊNCIAS}

BITENCOURT, Cezar Roberto. Tratado de Direito Penal: parte geral. 13 ed. atual. São Paulo: Saraiva, 2008. v. 1.

CONSELHO FEDERAL DE PSICOLOGIA. Atuação do psicólogo no sistema prisional. Brasília: CFP, 2010.

FAGUNDES, José. Universidade e Compromisso Social: Extensão, Limites e Perspectivas. Campinas: UNICAMP, 1986. v. 1.

MIRABETE, Júlio Fabbrini. Execução Penal: Comentários à Lei no 7.210, de 11-7-84. 10 ed. rev. e atual. São Paulo: Atlas, 2002.

PRADO, Luiz Regis. Curso de Direito Penal Brasileiro. 13 ed. ver. atual. e ampl. São Paulo: Ed. Revista dos Tribunais, 2014. 